\title{
Recent Trends in Medication Usage for the Treatment of Juvenile Idiopathic Arthritis and the Influence of Tumor Necrosis Factor Inhibitors
}

\author{
Melissa L. Mannion, Fenglong Xie, Jeffrey R. Curtis, and Timothy Beukelman
}

\begin{abstract}
Objective. Using administrative data from a large commercial US health insurer, we investigated temporal trends in medication use among children diagnosed with juvenile idiopathic arthritis (JIA). Methods. Children with $\geq 1$ physician diagnosis code for JIA in the calendar years 2005 through 2012 were included. Use of tumor necrosis factor inhibitors (TNFi), methotrexate (MTX), nonsteroidal antiinflammatory drugs (NSAID), and oral glucocorticoids (GC) was determined. Temporal changes in medication usage were evaluated with the Cochran-Armitage test for trend. We used paired t-tests to evaluate the use of NSAID and GC in the 6 months before and after new TNFi use.

Results. We identified 4261 unique individuals with JIA. The proportion of patients receiving TNFi increased from $8.7 \%$ in 2005 to $22.4 \%$ in 2012 ( $\mathrm{p}<0.0001$ ). MTX use increased from $18.4 \%$ to $23.2 \%(\mathrm{p}=0.02)$. NSAID use decreased from $49 \%$ to $40 \%(\mathrm{p}=0.02)$. GC use was relatively unchanged. Following new TNFi use, the mean number of NSAID prescriptions (among prevalent users) decreased from 2.8 to 2.0 ( $\mathrm{p}<0.0001$ ), and the mean daily GC dose (among prevalent users) decreased from $7.3 \mathrm{mg} /$ day to $3.9 \mathrm{mg} /$ day $(\mathrm{p}<0.0001)$. Many new TNFi users $(57 \%)$ had not used MTX in the previous 6 months, and only 37\% had any concurrent MTX use in the 6 months following new TNFi use.

Conclusion. TNFi use in the treatment of JIA increased 2- to 3-fold over the last 8 years. New TNFi use was associated with decreased NSAID and GC use. TNFi may be replacing, rather than complementing, MTX in the treatment of many patients. (First Release Aug 1 2014; J Rheumatol 2014;41:2078-84; doi:10.3899/jrheum.140012)
\end{abstract}

Key Indexing Terms:

JUVENILE IDIOPATHIC ARTHRITIS

METHOTREXATE TUMOR NECROSIS FACTOR INHIBITORS

The treatment of juvenile idiopathic arthritis (JIA) has changed dramatically over the last few decades, owing to the introduction of effective therapeutic agents and with the increasing recognition that JIA is usually not a self-limited condition ${ }^{1}$. The historical foundation of treatment of JIA had consisted of nonsteroidal antiinflammatory drugs (NSAID) and oral glucocorticoids (GC) in conjunction with targeted intraarticular GC injections of selected joints. In 1992,

From the Department of Pediatrics, Department of Medicine, and the Division of Rheumatology, University of Alabama at Birmingham, Birmingham, Alabama, USA.

Supported by an investigator-initiated research grant from Pfizer Inc. Dr Curtis was supported by US National Institutes of Health grant R01 HSO18517. JRC's research was supported by Roche/Genentech, UCB, Janssen, CORRONA, Amgen, Pfizer, BMS, Crescendo, and AbbVie. TB's consultant fees were supported from Novartis, Genentech, and UCB.

M.L. Mannion, MD, Pediatric Rheumatology Fellow; T. Beukelman, MD, MSCE, Associate Professor, Department of Pediatrics, and the Division of Rheumatology; F. Xie, MS; J.R. Curtis, MD, MS, MPH, Associate Professor, Department of Medicine, and the Division of Rheumatology, University of Alabama at Birmingham.

Address correspondence to Dr. T. Beukelman, University of Alabama at Birmingham, CPP 210, 1600 7th Ave. S., Birmingham, Alabama 35233, USA.E-mail: tbeukelman@peds.uab.edu

Accepted for publication May 15, 2014. methotrexate (MTX) was shown to be effective in the treatment of juvenile arthritis in a randomized placebo-controlled clinical trial ${ }^{2}$ and its use in routine clinical practice steadily increased. Similarly, in 2000, the first biologic agent, the tumor necrosis factor- $\alpha$ inhibitor (TNFi) etanercept (ETN), was shown to be effective in the treatment of JIA ${ }^{3}$. Additional TNFi have been shown to be effective in the treatment of JIA ${ }^{4,5}$, as have biologic agents with different mechanisms of action ${ }^{6,7,8,9}$. Also introduced into the market at about the same time as the first TNFi were the selective cyclooxygenase 2 (COX-2) inhibitors, 1 of which, celecoxib, was specifically studied in JIA and found to be at least as effective as naproxen ${ }^{10}$. The relative frequency with which celecoxib is used in clinical practice for the treatment of JIA is unclear. The addition of traditional disease-modifying antirheumatic drugs (DMARD) such as MTX and biologic DMARD has enabled many patients with JIA to achieve disease remission, which was previously infrequently attained ${ }^{1}$.

TNFi have continued to demonstrate effectiveness and safety in followup studies of randomized trials ${ }^{11,12}$ and have become fundamental to the treatment of JIA ${ }^{13}$, but little is known about the actual use of these medications in clinical

Personal non-commercial use only. The Journal of Rheumatology Copyright $@$ 2014 . All rights reserved. 
practice. Specifically, it is unclear the extent to which TNFi use has increased relative to MTX, NSAID, and GC use. Also unclear is the effect that initiating TNFi use has on the use of other medications at the individual patient level. One may suspect that the increased use of TNFi would be associated with decreased use of NSAID and GC owing to improved control of the signs and symptoms of disease, but this has not been well-studied. Systemic GC use has remained prevalent; a study of patients enrolled in the Childhood Arthritis and Rheumatology Research Alliance (CARRA) Registry reported that $42 \%$ of all children with a history of arthritis involving 5 or more joints had received GC during their disease courses ${ }^{14}$. Several randomized studies of adults with rheumatoid arthritis ${ }^{15}$ and at least 2 studies of children with $\mathrm{JIA}^{4,16}$ have demonstrated the superior effectiveness of combination therapy of TNFi plus MTX compared to TNFi alone, but it is unclear how often children receive this combination therapy. The American College of Rheumatology (ACR) Recommendations for the Treatment of JIA call for a trial of MTX prior to initiation of $\mathrm{TNFi}^{13}$, but whether this recommendation is followed in clinical practice is unclear.

Health insurer administrative claims data contain a reliable source of outpatient pharmacy fills and physician encounter diagnosis codes for each beneficiary that provide an accurate account of real-world medication use ${ }^{17}$. Using national claims data from a large commercial insurer, we sought to characterize the use of medications in the treatment of JIA over time and determine changes in therapy associated with the initiation of TNFi. We sought to determine the use of MTX prior to or concurrent with TNFi, and whether the initiation of a TNFi reduced the use of GC and prescription NSAID in patients with JIA.

\section{MATERIALS AND METHODS}

After obtaining Institutional Review Board approval, we performed our study using national commercial insurance administrative claims data from January 2005 through September 2012 with claims from all 50 US states and the District of Columbia. The commercial insurer provides medical coverage to more than 18 million individuals through numerous employer-sponsored and individual plans. For each calendar year, we included all patients who were age $\leq 16$ years at the start of the calendar year (to increase the sensitivity for newly diagnosed cases of JIA) and received at least 1 International Classification of Disease, 9th ed (ICD-9) code associated with a physician encounter that was consistent with JIA: 714 [juvenile rheumatoid arthritis (JRA)], 720 [spondyloarthropathy $(\mathrm{SpA})$ ], and 696.0 [psoriatic arthritis (PsA)]. Patients were included in the analysis for each year that they met the inclusion criteria.

In the analyses of yearly temporal trends in medication use, subjects were only included if they had full medical and pharmacy benefits for all 12 months of the respective calendar year (for the first 9 months in 2012). Medication use was defined by at least 1 pharmacy or infusion claim during the respective calendar year. Treatment with TNFi [adalimumab, ETN, infliximab (IFX), golimumab, or certolizumab], MTX, NSAID (including celecoxib, the only COX-2 inhibitor available during the study period), and oral GC, was determined. We performed a sensitivity analysis by requiring patients to receive at least 2 JIA diagnosis codes ( $>7$ days apart) in the same calendar year. We also evaluated medication use among children with at least 1 diagnosis code consistent with JIA and at least 1 ICD-9 diagnosis code for uveitis $(364.0,364.1,364.3)$ in the same calendar year.

New TNFi users were defined by having at least 6 months of preceding eligibility without evidence of any TNFi use and at least 6 months of followup data available following new TNFi initiation. Only the first instance of any new TNFi use was included for each individual patient. We assigned each new TNFi user to an arthritis diagnosis according to the most frequent ICD-9 code received during the 12-month new-user observation period: 714 (JRA), 720 (SpA), and 696.0 (PsA).

Patient characteristics were collected for all children with at least 1 JIA diagnosis code and the subset of new TNFi users. Significant changes in medication use over time were evaluated with the Cochran-Armitage test for trend. We compared the number of filled prescriptions for NSAID and the cumulative mean daily GC dose (in prednisone equivalents) before and after the initiation of TNFi using paired t-tests. These analyses were performed among 2 groups of patients: users of NSAID and GC during the 6-month period prior to new TNFi use (prevalent users), and all new TNFi users. The use of MTX before and after new TNFi use was evaluated. Patient characteristics associated with different patterns of MTX use were compared using chi-square and ANOVA. All p values were 2-sided and considered significant at values $\leq 0.05$. Data analyses were performed using JMP Version 10.0 and SAS software, Version 9.3 (SAS institute Inc.).

\section{RESULTS}

There were a total of 4261 unique patients with 1 JIA code (Table 1; with a range of 818 to 1004 patients per calendar yr) and 2532 with 2 JIA codes within the same calendar year (with a range of 550 to 617 patients per calendar yr) during the study period. Most of the patients had a diagnosis code for juvenile rheumatoid arthritis (714). The median age was 11 years old [interquartile range (IQR) 7-14], and most of the patients $(64.4 \%)$ were female. Only $34 \%$ of patients were included in more than 1 calendar year of the study results. There were 1497 unique prescriber identification numbers associated with filled MTX, TNFi, NSAID, and GC prescriptions for the 4261 unique patients during the study period.

Table 1. Patient characteristics for all children with $\geq 1$ JIA code and for new TNFi users. Data presented are n (\%) unless noted.

\begin{tabular}{|c|c|c|}
\hline Characteristics & $\begin{array}{l}\geq 1 \text { JIA code } \\
n=4261\end{array}$ & $\begin{array}{c}\text { New TNFi User, } \\
\mathrm{n}=344\end{array}$ \\
\hline Median age, yrs & 11 (IQR 7-14) & 13 (IQR 9-15) \\
\hline Female & $2742(64.4)$ & $230(66.9)$ \\
\hline \multicolumn{3}{|l|}{ US census region } \\
\hline Midwest & $609(14.3)$ & $51(14.8)$ \\
\hline Northeast & $1367(32.1)$ & $93(27.0)$ \\
\hline South & $1395(32.7)$ & $124(36.1)$ \\
\hline West & $890(20.9)$ & $76(22.1)$ \\
\hline \multicolumn{3}{|c|}{ JIA diagnosis codes } \\
\hline 714 & $3898(91.5)$ & $313(91.0)$ \\
\hline 720 & $334(7.8)$ & $40(11.6)$ \\
\hline 696.0 & $310(7.3)$ & $44(12.8)$ \\
\hline \multicolumn{3}{|c|}{ No. calendar years observed } \\
\hline $1 \mathrm{yr}$ & $2793(66)$ & $76(22.1)$ \\
\hline$\geq 2 \mathrm{yrs}$ & $1468(34)$ & $268(77.9)$ \\
\hline
\end{tabular}

JIA: juvenile idiopathic arthritis; TNFi: tumor necrosis factor inhibitors; IQR: interquartile range. 
The proportion of patients with JIA using MTX and TNFi significantly increased over time (Figure 1). In 2005, 8.7\% of patients with 1 JIA code received TNFi compared to $22.4 \%$ in $2012(\mathrm{p} \geq 0.0001)$. Over the same time period, the proportion of MTX users increased from $18.4 \%$ to $23.2 \%$ $(\mathrm{p}=0.02)$. Conversely, the proportion of NSAID users decreased from $49.2 \%$ in 2005 to $40.4 \%$ in $2012(\mathrm{p}=0.02)$. GC use did not exhibit a significant trend over time $(\mathrm{p}=$ 0.4 ); the proportions ranged from $19.8 \%$ in 2005 to $16.1 \%$ in 2012 with small increases and decreases from year to year.

When restricted to patients with 2 or more JIA diagnosis codes within the same calendar year, similar increases in MTX and TNFi use were observed. The increase in TNFi use was significant $(\mathrm{p}<0.0001)$, increasing from $13.6 \%$ in 2005 to $30.3 \%$ in 2012. The trend for MTX use was significant $(\mathrm{p}=0.05)$, with proportions increasing from $25.9 \%$ in 2005 to $32.4 \%$ in 2012. Use of NSAID decreased significantly over time, from $60.8 \%$ in 2005 to $44.2 \%$ in 2012 (p < $0.0001)$. Again, the use of GC did not demonstrate a trend $(p=0.2)$, with the proportion of users being $22.8 \%$ in 2005 and $19.3 \%$ in 2012 .

Among children with at least 1 diagnosis code for JIA and at least 1 diagnosis code for uveitis in each calendar year (total of 387 unique patients for all yrs), the proportion of TNFi use increased significantly from $11.0 \%$ in 2005 to $29.1 \%$ in $2012(\mathrm{p}<0.0001)$, similar to the trend seen among children with 2 or more diagnosis codes for JIA.

Over the study period, TNFi use increased dramatically compared to MTX use. In 2005, there were 0.6 users of any
TNFi for each individual user of MTX without use of TNFi. This ratio increased to 1.4 in 2012; that is, in 2012, there were $40 \%$ more children receiving TNFi (with or without concurrent MTX) than there were children receiving MTX without TNFi.

The use of celecoxib was uncommon throughout the study period. The prevalence of celecoxib use over the entire study period for children with $\geq 1$ JIA code was $4 \%$ without any evidence of trend over time $(p=0.2)$. Likewise, the proportion of prescription NSAID users that used selective COX-2 inhibitors remained relatively unchanged at about $7 \%$ over the study period.

Over the entire study period, ETN was used most frequently (71.5\% of all TNFi use), followed by adalimumab (28.6\%), and IFX (14.9\%). The proportion of ETN use reached its peak of $82.6 \%$ in 2007 and then decreased to $61.8 \%$ in 2011 (trend $\mathrm{p}<0.0001$ ). The proportion of IFX use was highest in $2005(17.7 \%)$ and then decreased to $12.4 \%$ in 2012 (trend $\mathrm{p}=0.1$ ). The proportion of adalimumab use steadily increased from $8.9 \%$ in 2005 to $33.1 \%$ in 2011 (trend $\mathrm{p}<0.0001$ ).

Other medications used for the treatment of inflammatory arthritis were infrequently used in this JIA population. Hydroxychloroquine and sulfasalazine were used in about $5 \%$ and $3 \%$ of the patients, respectively, over the entire study period. Abatacept, anakinra, leflunomide, rituximab, and tocilizumab were each used by fewer than $2 \%$ of patients in any calendar year.

We identified 344 new TNFi users. Some of their characteristics were different from all patients with JIA (Table 1),

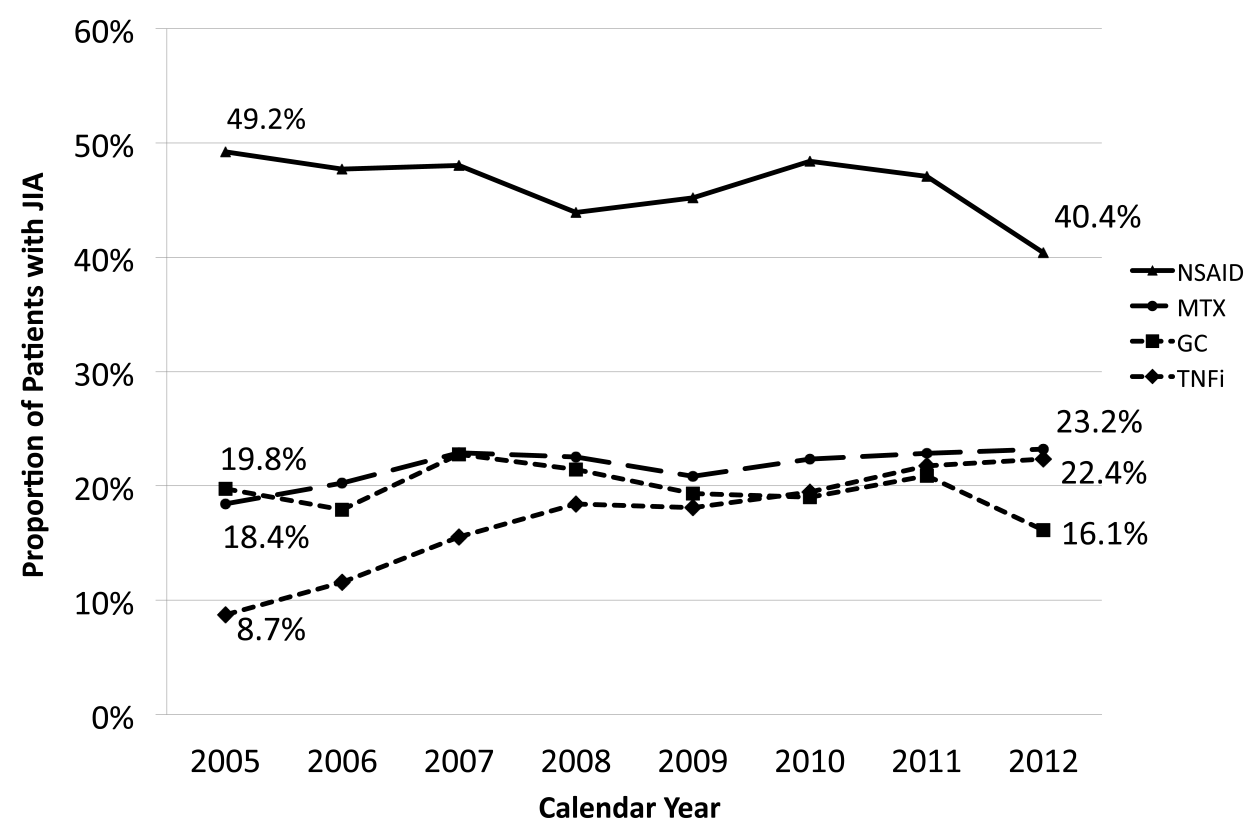

Figure 1. Proportion of patients with JIA receiving TNFi, MTX, NSAID, and GC by calendar year. JIA: juvenile idiopathic arthritis; TNFi: tumor necrosis factor inhibitors; MTX: methotrexate; NSAID: nonsteroidal antiinflammatory drugs; GC: glucocorticoids.

Personal non-commercial use only. The Journal of Rheumatology Copyright @ 2014 . All rights reserved. 
such as the duration of observation (78\% of new TNFi users with $\geq 2$ yrs of followup compared to $34 \%$ of all patients) and the frequency of diagnosis codes for PsA and SpA. (The duration of observation is longer in this subset of patients owing to the requirement for 6 months of baseline data and 6 months of followup data.) The most commonly initiated TNFi were ETN (70\%), adalimumab (19\%), and IFX (10\%).

One possible contributing factor to the increasing proportion of children with JIA receiving TNFi over time could be the initiation of TNFi therapy in progressively younger patients as physicians gained comfort with this new class of medications; however, this was not observed in our data. The median age of new TNFi users did not decrease over time and ranged from 11.5 years (IQR 9-13) in 2005 to 13 years (IQR 8-16) in 2012.

New TNFi use was associated with a reduction in the number of filled NSAID prescriptions (Table 2). This reduction was significant among prevalent NSAID users $(n=194)$, with a mean decrease of 0.85 prescriptions over the 6-month period following new TNFi use ( $\mathrm{p}<0.0001$ ).

New TNFi use was associated with a reduction in GC use (Table 3). In the 6 months following new TNFi use, there was a reduction in the mean daily dose of GC of $1.1 \mathrm{mg}$ per day among all new TNFi users $(\mathrm{p}=0.0002)$ and $3.4 \mathrm{mg}$ per day among prevalent users of GC $(p<0.0001)$. Among the prevalent users of GC, $60 \%$ (75/126) did not have GC use in the 6 months following initiation of TNFi. Conversely, 17 patients (5\% of all new TNFi users) who did not have GC use in the 6 months prior to new TNFi use received GC in the 6 months after new TNFi use at a mean dose of $3.5 \mathrm{mg} / \mathrm{day}$.
The use of MTX before and after new TNFi use did not necessarily follow the expected patterns (Table 4). Many patients $(57 \%)$ received new TNFi without having received MTX in the prior 6 months. Most patients with new TNFi use did not receive concurrent therapy with MTX; only 37\% of patients received any MTX in the 6 months following new TNFi use. The initiation of both new MTX and new TNFi concurrently was infrequent too; only $11 \%$ of children without MTX use in the 6 months prior to new TNFi use started using MTX in the following 6 month period. Of all new TNFi users, $51 \%$ did not receive MTX in the combined 12-month period.

The use of MTX before new TNFi varied based on the arthritis diagnosis. Patients with SpA $(n=30)$ or PsA $(n=$ 24) diagnoses had higher frequencies of TNFi use without prior MTX use (90\% and $75 \%$, respectively) compared to patients diagnosed with JRA (150/290, 51.7\%), and these differences were statistically significant $(\mathrm{p}<0.0001$ for both comparisons). There were no significant differences in the patterns of MTX use before or after TNFi use with respect to census region of residence $(p=0.7)$, age $(p=0.2)$, or presence of uveitis diagnosis codes $(\mathrm{p}=0.8)$.

The proportions of new TNFi users with MTX use before or after starting TNFi did not change significantly by year during the study period. When evaluating the use of MTX in the 12 months before and after new TNFi use, the results were similar. Specifically, $47 \%$ of new TNFi users did not receive MTX in the 12 months prior to new TNFi use and only $48 \%$ received any MTX in the 12 months following new TNFi use.

Table 2. The use of NSAID in the 6 months prior to and the 6 months following new initiation of TNFi use.

\begin{tabular}{|c|c|c|c|c|c|c|c|}
\hline $\begin{array}{l}\text { All new TNFi users, } \\
\mathrm{n}=344\end{array}$ & $194(56 \%)$ & $149(43 \%)$ & 0.0006 & $1.6(1.9)$ & $1.2(1.8)$ & $-0.4(0.2-0.6)$ & 0.0003 \\
\hline $\begin{array}{l}\text { Prevalent NSAID users, } \\
\mathrm{n}=194\end{array}$ & $194(100 \%)$ & $125(64 \%)$ & $<0.0001$ & $2.8(1.7)$ & $2.0(2.0)$ & $-0.9(0.5-1.2)$ & $<0.0001$ \\
\hline
\end{tabular}

NSAID: nonsteroidal antiinflammatory drugs; TNFi: tumor necrosis factor inhibitors.

Table 3. The use of GC in the 6 months prior to and the 6 months following new initiation of TNFi use.

\begin{tabular}{lccccccc}
\hline & $\begin{array}{c}\text { No. GC Users } \\
\text { Prior to New } \\
\text { TNFi Use }\end{array}$ & $\begin{array}{c}\text { No. GC Users } \\
\text { Following New } \\
\text { TNFi Use }\end{array}$ & $\mathrm{p}$ & $\begin{array}{c}\text { Mean Daily GC } \\
\text { Dose Prior to } \\
\text { New TNFi Use (SD) }\end{array}$ & $\begin{array}{c}\text { Mean Daily GC } \\
\text { Dose Following } \\
\text { New TNFi Use (SD) }\end{array}$ & $\begin{array}{c}\text { Mean Change } \\
\text { in Daily GC } \\
\text { Dose (95\% CI) }\end{array}$ \\
\hline $\begin{array}{c}\text { All new TNFi users, } \\
\mathrm{n}=344\end{array}$ \\
$\begin{array}{c}\text { Prevalent GC users, } \\
\mathrm{n}=126\end{array}$ & $126(37 \%)$ & $68(20 \%)$ & $<0.0001$ & $2.7 \mathrm{mg}(5.8)$ & $1.6 \mathrm{mg}(4.8)$ & $-1.1 \mathrm{mg}(0.5-1.6)$ & 0.0002 \\
\hline
\end{tabular}

GC: glucocorticoids (in prednisone equivalents); TNFi: tumor necrosis factor inhibitors. 
Table 4. The use of MTX in the 6 months prior to and the 6 months following new initiation of TNFi use.

MTX Use Following

New TNFi Use

\begin{tabular}{cccc}
\hline $\begin{array}{c}\text { MTX use prior to } \\
\text { new TNFi }\end{array}$ & Yes & No & Total \\
Yes & $108(31 \%)$ & $41(12 \%)$ & $149(43 \%)$ \\
No & $21(6 \%)$ & $174(51 \%)$ & $195(57 \%)$ \\
Total & $129(37 \%)$ & $215(63 \%)$ & \\
\hline
\end{tabular}

MTX: methotrexate; TNFi: tumor necrosis factor inhibitors.

\section{DISCUSSION}

Using data from a large national commercial health insurer in the United States, we analyzed recent changes in medication use in the treatment of JIA. The use of TNFi in the treatment of JIA increased 2- to 3-fold over the last 8 years, with a less pronounced increase in the use of MTX. Over the same time period, there was decreased use of prescription NSAID. At the individual patient level, new initiation of TNFi was followed by decreased use of NSAID and GC.

An analysis of medication use in the CARRA Registry, a prospective observational cohort of children enrolled by pediatric rheumatologists from more than 50 clinical sites in the United States, also reported about TNFi and MTX use in the treatment of $\mathrm{JIA}^{14}$. At the time of enrollment, $71 \%$ of patients had ever received MTX and 44\% had ever received TNFi. By comparison, we observed that among children with $\geq 2$ JIA diagnosis codes in 2012, 32\% received MTX and $30 \%$ received TNFi. The true discrepancy between these results is not easy to determine because the CARRA Registry study reported ever use and our current study reported on use per calendar year for an open cohort of children enrolled in the health insurance plan. We cannot accurately determine "ever use" from these data. Additionally, all children in the CARRA Registry are treated by pediatric rheumatologists, who identify individual patients and consent to their taking part; this likely affects the patients' characteristics and reflects treatment decisions made by pediatric rheumatologists. In contrast, our current study included unselected children diagnosed with JIA, irrespective of the treating physician or patient characteristics. It is not known how many children with JIA are treated by physicians other than pediatric rheumatologists in the United States, but the proportion is believed to be significant (i.e., greater than $40 \%)^{18,19}$. In our study, children diagnosed with JIA filled prescriptions for MTX, TNFi, NSAID, and GC that were associated with 1497 different unique prescriber identification numbers. Because there are only about 350 board certified pediatric rheumatologists in the United States, many other providers must be writing prescriptions for these medications.

Interestingly, there was a trend of decreasing prescription
NSAID use among patients with JIA. This appeared to coincide with the increased use of MTX and TNFi, and may reflect better overall disease control with fewer residual symptoms including pain. Use of celecoxib, a selective COX-2 inhibitor, remained uncommon in the JIA population without much variation in use over the last 8 years despite being approved by the US Food and Drug Administration for the treatment of JIA during the study period in December 2006. GC use among all patients remained prevalent and relatively stable during the study period, despite the increased use of MTX and TNFi. The reasons for this finding are unclear, but may reflect strong preferences for the use of GC by individual physicians. A related finding was reported in the aforementioned study of the CARRA Registry participants: about $9 \%$ of all patients with JIA were currently receiving GC at the time of enrollment despite the frequent use of MTX and TNFi in this cohort of patients ${ }^{14}$.

For individual patients, the new use of TNFi was followed by decreased use of prescription NSAID and GC. Ostensibly, this is the result of improved disease control with the use of $\mathrm{TNFi}$, consistent with published clinical trials ${ }^{3,4}$. In addition to improved disease control, this reduction in co-medication use may represent an important benefit of TNFi therapy when considering the potential adverse effects of chronic $\mathrm{NSAID}^{20}$ and especially, GC use ${ }^{21}$. (Of course, TNFi have potential adverse effects as well ${ }^{22}$.) The observed reduction in GC dose (mean $1.1 \mathrm{mg} /$ day reduction among all new TNFi users and $3.4 \mathrm{mg} /$ day reduction among prevalent GC users) is likely clinically significant. All-cause mortality and cardiovascular-related mortaælity have been shown to be significantly associated with small differences in daily GC dose (HR 1.07 per mg/day and 1.08 per mg/day, respectively) in adults with $\mathrm{RA}^{23}$.

The use of MTX and TNFi in our study population did not appear consistent with published recommendations or clinical studies of effectiveness. The ACR Recommendations clearly recommend a trial of MTX prior to the initiation of $\mathrm{TNFi}^{13}$. Despite this, only about $50 \%$ of new $\mathrm{TNFi}$ users had used MTX in the recent past. Of note, most of this study period predates the publication of the ACR Recommendations in April 2011. Numerous studies have demonstrated the superior treatment effect of TNFi used in combination with MTX compared to TNFi used alone $4,16,24$ Despite this, the majority of new TNFi users did not use concurrent MTX therapy in the year following initiation of TNFi. One possible clinical reason to initiate TNFi without first using MTX might be the concern about disease severity or poor prognosis. It may be believed that sometimes arthritis is too severe to tolerate a trial period of MTX. In this situation, the use of concurrent therapy with TNFi and MTX may be reasonably expected; however, this pattern of use was observed only infrequently. Admittedly, we could not observe events that occurred prior to enrollment in the health insurance plan ("left-censoring"). Thus, some

Personal non-commercial use only. The Journal of Rheumatology Copyright @ 2014 . All rights reserved. 
patients may have had a remote history of prior MTX use when we observed new TNFi use, but this is unlikely to represent the majority of patients. Overall, it appears that TNFi may be replacing MTX rather than complementing MTX among many patients and prescribers.

In general, TNFi are often more effective than MTX and may be better tolerated than MTX with respect to non-serious adverse drug experiences (e.g., nausea). This combination of positive factors may be perceived by prescribers as outweighing the increased direct medication cost of TNFi and the uncertain safety of TNFi use for durations beyond those observed thus far. It is unclear why more children did not receive concurrent therapy with TNFi and MTX, although this may also be related to the sometimes limited tolerability of $\mathrm{MTX}^{25}$.

Our study had important limitations. We used data from a single large private commercial insurer; medication use among patients with different insurance may be different. Nevertheless, the data are from a national population of beneficiaries without specific restriction to particular healthcare providers or geographic regions, and provide a more comprehensive view of prescription medication use in the real-world setting. Prescription patterns are influenced by myriad coverage policies in addition to provider preference, and could explain some of the patterns observed in the data. As over-the-counter medications are generally not covered by commercial insurance, it is not known how many patients received nonprescription NSAID during the study period.

Administrative claims data do not contain any clinical information including patient weight, and the diagnosis of JIA could not be confirmed for any of the patients. Accordingly, the numerical values of the proportions of children with medication use in our study are challenging to interpret because the number of children with true JIA in the denominator is uncertain. Nevertheless, the relative changes in medication use over time are valid reflections of medication use in the treatment of JIA, as one would not anticipate significant changes in the proportion of "false positive" or "rule-out" diagnoses codes for JIA over the time period of our study. We favored a highly sensitive definition of JIA to include all possible patients. An analysis using a more specific definition of JIA (2 diagnosis codes in a calendar year) resulted in increased proportions of medication use as expected, but importantly the overall trends in medication usage remained parallel to those using the more sensitive JIA definition.

We observed that there have been considerable changes in the treatment of JIA over the last 8 years, including the increased use of TNFi and the decreased use of prescription NSAID. The usage patterns of MTX and TNFi were surprising and did not appear consistent with published studies of effectiveness or current treatment recommendations that suggest that TNFi should be used after a trial of
MTX and then concurrently with MTX. Additional studies are warranted to better understand these medication usage trends and the factors that determine them.

\section{REFERENCES}

1. Ravelli A, Martini A. Juvenile idiopathic arthritis. Lancet 2007;369:767-78.

2. Giannini EH, Brewer EJ, Kuzmina N, Shaikov A, Maximov A, Vorontsov I, et al. Methotrexate in resistant juvenile rheumatoid arthritis. Results of the U.S.A.-U.S.S.R. double-blind, placebo-controlled trial. The Pediatric Rheumatology Collaborative Study Group and The Cooperative Children's Study Group. N Engl J Med 1992;326:1043-9.

3. Lovell DJ, Giannini EH, Reiff A, Cawkwell GD, Silverman ED, Nocton JJ, et al. Etanercept in children with polyarticular juvenile rheumatoid arthritis. Pediatric Rheumatology Collaborative Study Group. N Engl J Med 2000;342:763-9.

4. Lovell DJ, Ruperto N, Goodman S, Reiff A, Jung L, Jarosova K, et al. Adalimumab with or without methotrexate in juvenile rheumatoid arthritis. N Engl J Med 2008;359:810-20.

5. Ruperto N, Lovell DJ, Cuttica R, Woo P, Meiorin S, Wouters C, et al. Long-term efficacy and safety of infliximab plus methotrexate for the treatment of polyarticular-course juvenile rheumatoid arthritis: findings from an open-label treatment extension. Ann Rheum Dis 2010;69:718-22.

6. Ruperto N, Lovell DJ, Quartier P, Paz E, Rubio-Pérez N, Silva CA, et al. Abatacept in children with juvenile idiopathic arthritis: a randomised, double-blind, placebo-controlled withdrawal trial. Lancet 2008;372:383-91.

7. De Benedetti F, Brunner HI, Ruperto N, Kenwright A, Wright S, Calvo I, et al. Randomized trial of tocilizumab in systemic juvenile idiopathic arthritis. N Engl J Med 2012;367:2385-95.

8. Ruperto N, Brunner HI, Quartier P, Constantin T, Wulffraat N, Horneff $\mathrm{G}$, et al. Two randomized trials of canakinumab in systemic juvenile idiopathic arthritis. N Engl J Med 2012;367:2396-406.

9. Quartier P, Allantaz F, Cimaz R, Pillet P, Messiaen C, Bardin C, et al. A multicentre, randomised, double-blind, placebo-controlled trial with the interleukin-1 receptor antagonist anakinra in patients with systemic-onset juvenile idiopathic arthritis (ANAJIS trial). Ann Rheum Dis 201;70:747-54.

10. Foeldvari I, Szer IS, Zemel LS, Lovell DJ, Giannini EH, Robbins $\mathrm{JL}$, et al. A prospective study comparing celecoxib with naproxen in children with juvenile rheumatoid arthritis. J Rheumatol 2009;36:174-82.

11. Lovell DJ, Reiff A, Ilowite NT, Wallace CA, Chon Y, Lin SL, et al Safety and efficacy of up to eight years of continuous etanercept therapy in patients with juvenile rheumatoid arthritis. Arthritis Rheum 2008;58:1496-504.

12. Prince FH, Twilt M, ten Cate R, van Rossum MA, Armbrust W, Hoppenreijs EP, et al. Long-term follow-up on effectiveness and safety of etanercept in juvenile idiopathic arthritis: the Dutch national register. Ann Rheum Dis 2009;68:635-41.

13. Beukelman T, Patkar NM, Saag KG, Tolleson-Rinehart S, Cron RQ, DeWitt EM, et al. 2011 American College of Rheumatology recommendations for the treatment of juvenile idiopathic arthritis: initiation and safety monitoring of therapeutic agents for the treatment of arthritis and systemic features. Arthritis Care Res 2011;63:465-82.

14. Beukelman T, Ringold S, Davis TE, DeWitt EM, Pelajo CF, Weiss $\mathrm{PF}$, et al. Disease-modifying antirheumatic drug use in the treatment of juvenile idiopathic arthritis: a cross-sectional analysis of the CARRA Registry. J Rheumatol 2012;39:1867-74.

15. Upchurch KS, Kay J. Evolution of treatment for rheumatoid

Personal non-commercial use only. The Journal of Rheumatology Copyright (C) 2014. All rights reserved 
arthritis. Rheumatology 2012;51 Suppl 6:vi28-36.

16. Horneff G, De Bock F, Foeldvari I, Girschick HJ, Michels H, Moebius D, et al. Safety and efficacy of combination of etanercept and methotrexate compared to treatment with etanercept only in patients with juvenile idiopathic arthritis (JIA): preliminary data from the German JIA Registry. Ann Rheum Dis 2009;68:519-25.

17. Schneeweiss S, Avorn J. A review of uses of health care utilization databases for epidemiologic research on therapeutics. J Clin Epidemiol 2005;58:323-37.

18. Sherry DD, Wallace CA, Kahn SJ. Pediatric rheumatology in adult rheumatology practices in Washington state. Arthritis Rheum 1996;39:1218-21.

19. Mayer ML, Sandborg CI, Mellins ED. Role of pediatric and internist rheumatologists in treating children with rheumatic diseases. Pediatrics 2004;113:e173-81.

20. American College of Rheumatology Ad Hoc Group on Use of Selective and Nonselective Nonsteroidal Antiinflammatory Drugs. Recommendations for use of selective and nonselective nonsteroidal antiinflammatory drugs: an American College of Rheumatology white paper. Arthritis Rheum 2008;59:1058-73.
21. McDonough AK, Curtis JR, Saag KG. The epidemiology of glucocorticoid-associated adverse events. Curr Opin Rheumatol 200;20:131-7.

22. Shenoi S, Wallace CA. Tumor necrosis factor inhibitors in the management of juvenile idiopathic arthritis: an evidence-based review. Paediatr Drugs 2010;12:367-77.

23. Del Rincón I, Battafarano DF, Restrepo JF, Erikson JM, Escalante A. Glucocorticoid dose thresholds associated with all-cause and cardiovascular mortality in rheumatoid arthritis. Arthritis Rheumatol 2014;66:264-72.

24. Nam JL, Winthrop KL, van Vollenhoven RF, Pavelka K, Valesini G, Hensor EM, et al. Current evidence for the management of rheumatoid arthritis with biological disease-modifying antirheumatic drugs: a systematic literature review informing the EULAR recommendations for the management of RA. Ann Rheum Dis 2010;69:976-86.

25. Bulatović M, Heijstek MW, Verkaaik M, van Dijkhuizen EH, Armbrust W, Hoppenreijs EP, et al. High prevalence of methotrexate intolerance in juvenile idiopathic arthritis: development and validation of a methotrexate intolerance severity score. Arthritis Rheum 2011;63:2007-13. 